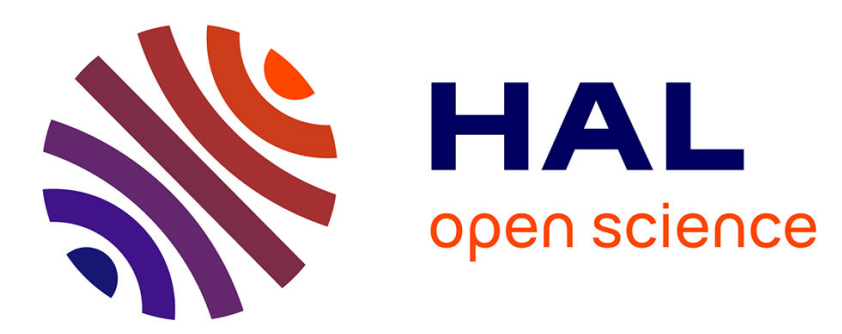

\title{
Interactions of grape tannins and wine polyphenols with a yeast protein extract, mannoproteins and $\beta$-glucan
} Julie Mekoue Nguela, Celine Poncet-Legrand, N. Sieczkowski, Aude Vernhet

\section{To cite this version:}

Julie Mekoue Nguela, Celine Poncet-Legrand, N. Sieczkowski, Aude Vernhet. Interactions of grape tannins and wine polyphenols with a yeast protein extract, mannoproteins and $\beta$-glucan. Food Chemistry, 2016, 210, pp.671-682. 10.1016/j.foodchem.2016.04.050 . hal-01496813

\section{HAL Id: hal-01496813 https://hal.science/hal-01496813}

Submitted on 27 May 2020

HAL is a multi-disciplinary open access archive for the deposit and dissemination of scientific research documents, whether they are published or not. The documents may come from teaching and research institutions in France or abroad, or from public or private research centers.
L'archive ouverte pluridisciplinaire HAL, est destinée au dépôt et à la diffusion de documents scientifiques de niveau recherche, publiés ou non, émanant des établissements d'enseignement et de recherche français ou étrangers, des laboratoires publics ou privés. 


\section{Accepted Manuscript}

Interactions of Grape tannins and Wine Polyphenols with a Yeast Protein Extract, Mannoproteins and $\beta$-glucan

J. Mekoue Nguela, C. Poncet-Legrand, N. Sieczkowski, A. Vernhet

PII:

$$
\text { S0308-8146(16)30567-2 }
$$

DOI: http://dx.doi.org/10.1016/j.foodchem.2016.04.050

Reference: FOCH 19057

To appear in:

\section{Food Chemistry}

Received Date: $\quad 19$ October 2015

Revised Date: $\quad 15$ April 2016

Accepted Date: $\quad 15$ April 2016

Please cite this article as: Mekoue Nguela, J., Poncet-Legrand, C., Sieczkowski, N., Vernhet, A., Interactions of Grape tannins and Wine Polyphenols with a Yeast Protein Extract, Mannoproteins and $\beta$-glucan, Food Chemistry (2016), doi: http://dx.doi.org/10.1016/j.foodchem.2016.04.050

This is a PDF file of an unedited manuscript that has been accepted for publication. As a service to our customers we are providing this early version of the manuscript. The manuscript will undergo copyediting, typesetting, and review of the resulting proof before it is published in its final form. Please note that during the production process errors may be discovered which could affect the content, and all legal disclaimers that apply to the journal pertain. 


\section{Interactions of Grape tannins and Wine Polyphenols with a Yeast Protein Extract, Mannoproteins and $\beta$-glucan.}

Mekoue Nguela J. ${ }^{1,2}$, Poncet-Legrand C. ${ }^{1}$, Sieczkowski N. ${ }^{2}$ and Vernhet A.*1 1 - UMR SPO: SPO, INRA, Montpellier SupAgro, Université de Montpellier,-34060 Montpellier, France 2 - Lallemand SAS, 19 rue des Briquetiers, BP 59, 31702 Blagnac, France

*Corresponding author :

Aude Vernhet, Montpellier SupAgro, UMR 1083 Sciences pour l'œnologie (SPO), bât. 28, 2 place Viala, F-34060 Montpellier, France.

Phone: 33 (0)4 99612758

Fax: $33(0) 499612857$

Email address: aude.vernhet@ supagro.fr 


\section{Abstract}

At present, there is a great interest in enology for yeast derived products to replace aging on lees in winemaking or as an alternative for wine fining. These are yeast protein extracts (YPE), cell walls and mannoproteins. Our aim was to further understand the mechanisms that drive interactions between these components and red wine polyphenols. To this end, interactions between grape skin tannins or wine polyphenols or tannins and a YPE, a mannoprotein fraction and a $\beta$-glucan were monitored by binding experiments, ITC and DLS. Depending on the tannin structure, a different affinity between the polyphenols and the YPE was observed, as well as differences in the stability of the aggregates. This was attributed to the mean degree of polymerization of tannins in the polyphenol fractions and to chemical changes that occur during winemaking. Much lower affinities were found between polyphenols and polysaccharides, with different behaviors between mannoproteins and $\beta$-glucans.

Keywords: Interactions; ITC; DLS; yeast protein extract; mannoproteins; $\beta$-glucans, grape and wine polyphenols.

\section{Introduction}


In recent years, a large variety of commercial products obtained from the yeast cells have been developed to promote red wine sensory characteristics, such as astringency, texture, color and mouthfeel (Escot, Feuillat, Dulau, \& Charpentier, 2001; Palomero et al., 2009; Del Barrio-Galán, Pérez-Magariño, Ortega Heras, \& Charpentier, 2001; Alcalde-Eon, GarcíaEstévez, Puente, Rivas-Gonzalo, \& Escribano-Bailón, 2014). These products are inactivated yeasts (IY), cell walls (CW) and mannoproteins (MPs) in the context of wine aging and yeast protein extracts (YPEs) for wine fining (Charpentier, Caillet, \& Feuillat, 2006; Iturmendi, Durán, Marín-Arroyo, \& Marin-Arroyo, 2010; Lochbühler et al., 2014). Their impact is attributed to interactions between red wine polyphenols and these yeast derived products (YDPs).

In the case of IY, CW and MPs, this impact has been attributed to the release of yeast mannoproteins (Guadalupe, Martínez, \& Ayestarán, 2010; Loira et al., 2013; Pozo-Bayón, Andújar-Ortiz, Alcaide-Hidalgo, Martin-Alvarez, \& Moreno-Arribas, 2009; Rodrigues, Ricardo-da-silva, Lucas, \& Laureano, 2012) in wine or to polyphenol adsorption on yeast cell walls, and especially on the outer mannoprotein layer (Mazauric \& Salmon, 2005; Morata et al., 2003). Thus, physico-chemical interactions between MPs and polyphenols are regarded as a key mechanism. Although $\beta$-glucans are also major components of cell walls, their potential role has never been considered. When dealing with YPEs and the fining of red wines, proteinpolyphenol interactions are expected to be decisive. Fining is used to soften tannic agressivity/intensity, to improve mouthfeel or to improve filterability or stabilization with regards to the precipitation of colloidal coloring matter. The effect of fining proteins is mostly related to their ability to interact with wine polyphenols and especially tannins (Granato et al., 2010).

In spite of a growing interest for the use of these YDPs in enology, the exact mechanisms involved in their potential effect on wine quality (clarification, sensory 
characteristics and wine stability) remain poorly understood. This is related: i) to the diversity of the products proposed and to their complex composition and ii) to the variability of red wine composition. In our previous works, we focused on studying polyphenols interactions with different YDPs (dead and inactivated yeast, yeast cell walls) obtained from the same enological Saccharomyces cerevisiae strain. The adsorption of grape tannins and wine polyphenols was studied by means of adsorption isotherms (Mekoue Nguela, Sieczkowski, Roi, \& Vernhet, 2015a). Interactions between polyphenols and cell walls were observed, but purified cell walls resulted in about 10-fold lower polyphenol retention than that obtained with whole yeast. We demonstrated later by means of confocal fluorescence and transmission electron microscopy that polyphenols cross the cell envelope barrier (cell wall and plasma membrane) of dead yeast and interact with cytoplasm constituents (Mekoue Nguela, Vernhet, Sieczkowski, \& Brillouet, 2015b). This explained the quantitative differences observed between whole inactivated cells and cell walls. As proteins in yeast represent 40 to $50 \%$ of the cell dry weight (Wiederhold, Veenhoff, Poolman, \& Slotboom, 2010), it was supposed that the cytoplasmic constituents involved were mainly proteins. These microscopic observations clearly showed that mannoproteins interact with tannins, but nothing could be concluded concerning $\beta$-glucans.

The present study has aimed to further explore interaction mechanisms between polyphenols and yeast components by: (i) studying interactions in solution between polyphenols and a yeast protein extract and (ii) comparing YPE/polyphenol interactions with mannoprotein/polyphenols and $\beta$-glucan/polyphenols interactions in solution. Interactions were studied using three different polyphenols fractions: grape skin tannins, a total polyphenols extract purified from a red wine and tannins purified from this extract.

\section{Materials and methods}




\subsection{Yeast Protein Extract}

The YPE was provided by Lallemand (Montreal, Canada). It was obtained from a biomass of a commercial Saccharomyces cerevisiae strain used in enology. The yeast biomass was produced according to the industrial process, in aerobic conditions. Intracellular proteins were extracted using a treatment likely to avoid their hydrolysis and the extract was spraydried. Residual water accounted for about $6 \%(\mathrm{w} / \mathrm{w})$ of the powder, which was stored at $4{ }^{\circ} \mathrm{C}$ before use. The YPE powder was first rehydrated in water under stirring for $15 \mathrm{~min}$ at a concentration of 100 g. $\mathrm{L}^{-1}$. It contained an insoluble fraction, which was removed by centrifugation $\left(15000 \mathrm{~g}, 15 \mathrm{~min}, 15^{\circ} \mathrm{C}\right)$ and represented $13 \%$ w/w (weighed after lyophilization) of the initial YPE powder. The soluble fraction $(87 \% \mathrm{w} / \mathrm{w})$ was further characterized and used for interaction studies.

Soluble polymers were separated from oligomers by ultrafiltration. To this end, $10 \mathrm{~mL}$ of YPE (concentration 87 g.L $\mathrm{L}^{-1}$ ) were introduced in a $50 \mathrm{~mL}$ centrifugal filter unit equipped with a $10 \mathrm{kDa}$ membrane (Amicon, Millipore) and centrifuged at $6000 \mathrm{~g}$ during $10 \mathrm{~min}$, at a temperature of $15^{\circ} \mathrm{C}$. The permeate was recovered and the retentate diafiltrated several times to remove the residual small solutes. Samples were freeze-dried to determine the proportion of oligomers (molecular weight $<10 \mathrm{kDa}$ ) and polymers (molecular weight $>10 \mathrm{kDa}$ ) and used for further analyses: total nitrogen, proteins and carbohydrates). Total nitrogen was determined by the Kjeldahl method using a Büchi digestion unit K-435 system and a Büchi distillation unit K-314 system. $30 \mathrm{mg}$ of samples were used for this analysis. Proteins in the YPE were analyzed by 1D SDS-PAGE electrophoresis, performed on a 14\% acrylamide resolving gel (gel length, $60 \mathrm{~mm})$. The YPE soluble $\left(10\right.$ g. $\left.\mathrm{L}^{-1}\right)$ was dissolved twice in a Laemmli $2 \mathrm{X}$ buffer and $30 \mu \mathrm{L}$ were loaded on the gel. A low molecular weight calibration kit (14.4 to $97 \mathrm{kDa}$, Pharmacia, Biotech) was included in the electrophoretic run. Gels were stained with $0.1 \%$ 
Coomassie Brilliant Blue R-250 (Biorad) in $40 \%$ of ethanol, $10 \%$ acetic acid and destained overnight in $10 \%$ acetic acid. Gels were then scanned at 300 dpi with an image scanner (GE Biosciences). Neutral glycosyl-residues were quantified in the YPE fractions after hydrolysis by converting the monosaccharides into their alditol acetate derivatives (Albersheim, Nevins, English, \& Karr, 1967). Analyses were performed on $2 \mathrm{mg}$ of samples. Inositol and allose (100 $\mu \mathrm{L}$ of a $1 \mathrm{mg} \cdot \mathrm{mL}^{-1}$ solution) were added as internal standards before reduction and acetylation. The quantification was performed by GC analysis using a fused silica DB-225 (temperature programming: $170{ }^{\circ} \mathrm{C}$ for $15 \mathrm{~min}, 170{ }^{\circ} \mathrm{C}-210{ }^{\circ} \mathrm{C}$ at $\left.1{ }^{\circ} \mathrm{C} \cdot \mathrm{min}^{-1}\right)$ capillary column $(30 \mathrm{~m} \mathrm{x} 0.25$ $\mu \mathrm{m} \times 0.25 \mathrm{~mm}$ ID) with $\mathrm{H}_{2}$ as the carrier gas and a SHIMADZU GC-2010-Plus gas chromatograph. Alditol acetate derivatives were identified on the basis of their retention time by reference to standard monosaccharides. Neutral sugar amount was calculated relative to the allose (Albersheim et al., 1967).

\subsection{Mannoproteins}

A commercial solution of Saccharomyces cerevisiae mannoproteins, commonly used in enology, was fractionated by ultrafiltration on a $10 \mathrm{kDa}$ membrane (GE-Healthcare, Hollow fiber cartridge filter, VFP-10-C-4M) to recover the high molecular weight fraction (> $10 \mathrm{kDa})$. Residual small solutes and oligosaccharides in the retentate obtained by UF were removed by diafiltration with water (up to a final dilution factor of 1000). The high molecular weight fraction was conserved at $4{ }^{\circ} \mathrm{C}$ with sodium azide $(0.02 \% \mathrm{w} / \mathrm{v})$ until use. The dry weight per milliliter of solution, $66 \mathrm{mg} \cdot \mathrm{mL}^{-1}$, was determined by freeze-drying of aliquots. Neutral sugars (Dallies, François, \& Paquet, 1998) and Kjeldhal analyses indicated a mannose content of 55\% $(\mathrm{w} / \mathrm{w})$ and a total nitrogen content of $1.6 \%(\mathrm{w} / \mathrm{w})$, indicating an average protein moiety in the mannoproteins of $10 \%$. The molecular weight distribution of the mannoproteins, between 14 to 
$500 \mathrm{kDa}$, was determined by high-resolution size exclusion chromatography (Ducasse et al., 2010).

\subsection{Laminarin}

Laminarin from Laminaria digitata (brown seaweed) was purchased from SigmaAldrich. Laminarin is a low molecular weight $(6 \mathrm{kDa})$ and water-soluble $\beta$-glucan, composed of a linear $\beta$-(1,3)-glucan chain with $\beta$-(1,6)-linkages. It was used in this study to evaluate interactions between tannins and $\beta$-glucans.

\subsection{Polyphenol isolation and analysis}

A wine polyphenol extract WP was purified from a Merlot wine elaborated in 2012 at the INRA Experimental Unit of Pech Rouge (Gruissan, France), as previously described (Mekoue Nguela et al., 2015a). The WP was stored at $-80{ }^{\circ} \mathrm{C}$ under argon atmosphere before further use. Spectrophotometric analyses were made with a SAFAS UV-MC ${ }^{2}$ spectrophotometer (Monaco) on the powder dissolved in a model wine at a concentration of 5 g. $\mathrm{L}^{-1}$. This provided an absorbance at $280 \mathrm{~nm}$ of 55.0 (Total Polyphenol Index, TPI), corresponding to that of the initial wine. The color intensity $\left(\mathrm{A}_{420 \mathrm{~nm}}+\mathrm{A}_{520 \mathrm{~nm}}+\mathrm{A}_{620 \mathrm{~nm}}\right.$, optical path $1 \mathrm{~cm})$ of the reconstituted wine was $16.1 \pm 0.5$ and its tint $\left(\mathrm{A}_{420 \mathrm{~nm}} / \mathrm{A}_{520 \mathrm{~nm}}\right.$, optical path 1 $\mathrm{cm})$ was $0.55 \pm 0.12$. Accounting for the presence of residual sugars and nitrogenous compounds in the fraction (15\%), a TPI of 55.0 corresponded to a whole polyphenol concentration of $4.3 \mathrm{~g}$ g. $\mathrm{L}^{-1}$. This value was used to convert TPI into polyphenol amount. Polyphenol monomers were analyzed by HPLC-DAD according to the procedure described in Ducasse et al. (Ducasse et al., 2010). Tannins were analyzed by HPLC after acid-catalyzed 
depolymerization reaction in the presence of a nucleophilic agent. Considering the low yield obtained with usual phloroglucinolysis (Mekoue Nguela et al., 2015a), the acid-catalyzed cleavage was carried out in the presence of excess 2-mercaptoethanol, according to the protocol developed by Roumeas et al. (Roumeas, Aouf, Dubreucq \& Fulcrand, 2013). Mercaptolysis was carried out during $2 \mathrm{~h}$ at $40{ }^{\circ} \mathrm{C}$ in methanol with $0.1 \mathrm{M} \mathrm{HCl}$ and $100 \mu \mathrm{L} \cdot \mathrm{mL}^{-1}$ 2mercaptoethanol. Concentrations were set at about $1 \mathrm{mg} \cdot \mathrm{mL}^{-1}$. HPLC analysis was performed using an Alliance Waters system (Milford, MA, USA) equipped with a photodiode array detector, a fluorimeter and a millennium data manager software. The column was a reversed phase Atlantis C18 $(250 \times 2.1 \mathrm{~mm}, 5 \mu \mathrm{m}$ packing $)$ protected with a guard column of the same material ( $20 \times 2.1 \mathrm{~mm}, 5 \mu \mathrm{m}$ packing, Milford, MA, USA). Oven temperature was set at $38^{\circ} \mathrm{C}$. The solvent system (flow rate was $0.25 \mathrm{~mL} \cdot \mathrm{min}^{-1}$ ) was a gradient of solvent A (water/formic acid, 95:5, v/v) and solvent B (acetonitrile/water/formic acid, 80:15:5, v/v/v): proportions of solvent B were as follows: 0-5 min with 0\% B; 5-35 min, 0-10\%; 35-75 $\mathrm{min}, 10-20 \%$; 75-80 min, 20-100\%; and 80-90 min, 100-0\%. The injection volume for all samples was $5 \mu \mathrm{L}$. Calibration curves were established at $280 \mathrm{~nm}$ using external flavan-3-ol monomer standards (catechin, epicatechin, epigallocatechin and epicatechin-gallate).

High molecular weight tannins were isolated from the wine polyphenol pool WP dissolved in $\mathrm{H}_{2} \mathrm{O} / 0.05 \%$ TFA at a concentration of $43 \mathrm{mg} \cdot \mathrm{mL}^{-1}$. A column packed with Fractogel® EMD Phenyl (S) (Millipore, France, $226 \mathrm{~mL}$ bed volume) was equilibrated with $\mathrm{H}_{2} \mathrm{O} / 0.05 \%$ TFA (450 mL) prior to loading $5 \mathrm{~mL}$ of the extract. The column was then extensively washed with $\mathrm{H}_{2} \mathrm{O} / \mathrm{TFA} 0.05 \%$ (450 mL). Elution by $55 \% \mathrm{EtOH} / 45 \% \mathrm{H}_{2} \mathrm{O} / 0.05 \%$ TFA (315 mL) was performed first to remove low molecular weight polyphenols. The high molecular weight tannins were eluted with $60 \%$ acetone/ $40 \% \mathrm{H}_{2} \mathrm{O} / 0.05 \%$ TFA $(420 \mathrm{~mL})$. Solvents were evaporated under vacuum at $30{ }^{\circ} \mathrm{C}$ and the aqueous residues freeze-dried and 
weighed. The high molecular weight fraction, named WT, was stored at $-80{ }^{\circ} \mathrm{C}$ until use. Its composition was characterized by mercaptolysis, as described before.

A tannin fraction from Muscat grape skin (Vitis vinifera), previously purified at the laboratory and stored at $-80{ }^{\circ} \mathrm{C}$ under argon in sealed vials, was used for the experiments. This fraction was obtained by chromatography from a whole tannin fraction extracted from skin in the same conditions as the ones described before for wine tannins. The composition of the fraction was determined by UPLC after acid-catalyzed cleavage in the presence of thioglycolic acid (Prieur, Rigaud, Cheynier, \& Moutounet, 1994).

\subsection{Binding experiments}

Binding experiments were performed in a model wine composed of $12 \% \mathrm{v} / \mathrm{v}$ ethanol and 2 g. $\mathrm{L}^{-1}$ tartaric acid, the $\mathrm{pH}$ of which was adjusted to 3.5 with $\mathrm{KOH} 1 \mathrm{M}$. The ionic strength was set at $50 \mathrm{mM}$ by $\mathrm{NaCl}\left(2.16 \mathrm{~g} \cdot \mathrm{L}^{-1}\right) . \mathrm{SO}_{2}\left(25 \mathrm{mg} \cdot \mathrm{L}^{-1}\right)$ was added to prevent polyphenol oxidation. YPE $(10 \mathrm{mg})$ was re-hydrated in water $(1 \mathrm{~mL})$ for $15 \mathrm{~min}$ and centrifuged at $15000 \mathrm{~g}$ during $15 \mathrm{~min}$ to remove insoluble. The supernatant was recovered and a concentrated winelike solution was added to obtain the model wine composition described above and a final concentration of YPE of 3.48 g.L $\mathrm{L}^{-1}$. Polyphenol stock solutions were prepared by dissolving WP, WT or GST in the model wine at a concentration of $10 \mathrm{~g} . \mathrm{L}^{-1}$. These stock solutions were diluted to get final concentrations between 0.5 and 4 g.L $\mathrm{L}^{-1}$.

All experiments were carried out by mixing equal volumes of a $2 \mathbf{x}$ g.L ${ }^{-1}$ polyphenol solution ( $\mathbf{x}$ being the final desired concentration) and of a 3.48 g.L $\mathrm{L}^{-1}$ YPE solution (final concentration 1.74 g. $\mathrm{L}^{-1}$ ). Data represent a mean of at least two separate experiments. Samples $(2 \mathrm{~mL})$ were placed in $2 \mathrm{~mL}$ tightly closed eppendorfs in order to minimize headspace and were stirred continuously (Stuart rotator SB3, $40 \mathrm{rpm}$ ) in darkness and at room temperature. From preliminary kinetic trials, a contact time of $24 \mathrm{~h}$ was chosen. After 24 hours, samples were 
clarified by centrifugation $\left(15000 \mathrm{~g}, 15 \mathrm{~min}, 15{ }^{\circ} \mathrm{C}\right)$ and supernatants recovered for spectrophotometric measurements and HPLC analyses (WP only). The total polyphenol concentrations in the bulk were determined by absorbency measurements at $280 \mathrm{~nm}$ after adequate dilution. Total precipitated polyphenols (TAP) were calculated from the difference in absorbency between the samples and the corresponding controls using:

$$
T A P=T P I^{\text {PPcontrol }}-\left(T P I^{\text {sample }}-A_{280}{ }^{\text {YPEcontrol }}\right)
$$

$T P I^{\text {PPcontrol }}$ being the total polyphenol index $\left(\mathrm{A}_{280} \mathrm{x}\right.$ dilution factor) of the polyphenol solution before contact with YPE, $T P I^{\text {sample }}$ the one of the supernatant recovered after contact with YPE and $A_{280}{ }^{\text {YPEcontrol }}$ the absorbency of YPE controls. The latter is related to the presence in YPE of compounds that absorb at $280 \mathrm{~nm}$ (eg. aromatic amino acids). Although very low by comparison to the one of polyphenols, this absorbency affected measurements at the lowest polyphenol concentrations. Absorbency measurements at 420, 520 and $620 \mathrm{~nm}$ were also performed with WP. Residual proteins in the supernatants after interaction experiments were precipitated by a double precipitation procedure using trifluoroacetic acid and $70 \% \mathrm{w} / \mathrm{w}$ acetone/water (F.-X. Sauvage, personal communication), that allows their separation from polyphenols, and analyzed by 1D - SDS PAGE as described before.

The pellets obtained by centrifugation after binding experiments were re-suspended in $2 \mathrm{~mL}$ of model wine without polyphenols. Samples were stirred for $24 \mathrm{~h}$, centrifuged and the supernatants recovered. The reversibility upon dilution was evaluated through the quantity of polyphenols recovered in supernatants, measured by absorbency at $280 \mathrm{~nm}$.

\subsection{Dynamic light scattering}


DLS experiments were performed to study aggregation and aggregation kinetics between YPE, mannoproteins and laminarin and the different polyphenols (WP, WT and GST). They were carried out by mixing equal volumes of polyphenol and macromolecule solutions in the model wine. Final concentrations were set first at 0.4 g. $\mathrm{L}^{-1}$. For wine polyphenols (WT, WP) and YPE, concentrations were increased up to 2 and $1.74 \mathrm{~g} . \mathrm{L}^{-1}$, respectively. Interactions were followed over $24 \mathrm{~h}$, time zero being the mixing of the solutions.

DLS measurements were carried out on a Malvern zetasizer 3000 HS (Malvern instruments, Malvern, U.K.) equipped with a $10 \mathrm{~mW}$ He-Ne laser $(633 \mathrm{~nm})$, at an angle of $90^{\circ}$ to the incident beam. The sample cell was maintained at a temperature of $25{ }^{\circ} \mathrm{C}$. The time dependence of the scattered light was monitored, and the autocorrelation function $G(t)$ of the scattering species determined. The diffusion coefficient of the scattering species $(D)$, derived from this function, allowed the calculation of their hydrodynamic diameters, $\mathrm{D}_{\mathrm{H}}$, using the Stokes-Einstein equation (assuming that all scattering species were spherical):

$$
\mathrm{D}=(\mathrm{kT}) /\left(3 \pi \eta \mathrm{D}_{\mathrm{H}}\right)
$$

where $\mathrm{k}$ is the Boltzmann constant, $\mathrm{T}$ the temperature and $\eta$ the solvent viscosity. The cumulant method was used to fit the autocorrelation curves, and to calculate the average hydrodynamic diameter $\mathrm{D}_{\mathrm{H}}$ and the polydispersity index PI of the dispersion (PI varies between 0 and 1). Each measurement was the average of 10 subruns.

2.7. Titration Microcalorimetry A VP-ITC instrument (MicroCal, Northampton, MA) was used to measure enthalpy changes associated with interactions between yeast protein extractpolyphenols; mannoproteins-polyphenols and laminarin-polyphenols in the model wine. All experiments were performed at $25^{\circ} \mathrm{C}$ and additional experiments were performed at $10{ }^{\circ} \mathrm{C}$ with GST and WP. In a typical experiment, the macromolecule solution (YPE, mannoproteins or 
laminarin) was placed in the $1.448 \mathrm{~mL}$ sample cell of the calorimeter and the polyphenol solution (typically 5 g. $\mathrm{L}^{-1}$ ) was loaded into the injection syringe. The polyphenol solution was titrated into the sample cell as a sequence of 48 injections of $6 \mu \mathrm{L}$ aliquots. The duration of each injection was $12 \mathrm{~s}$, and the time delay to allow equilibration between successive injections was $8 \mathrm{~min}$. The sample cell was stirred throughout the experiment at $300 \mathrm{rpm}$ to ensure thorough mixing. Raw data obtained as a plot of heat flow (microcalories per second) against time (seconds) were then integrated peak-by-peak and normalized to obtain a plot of observed enthalpy change $(\Delta \mathrm{H})$ per $\mu \mathrm{g}$ of injectant against the massic ratio (polyphenols/macromolecules). Peak integration was performed using Microcal Origin (Microcal Software, Northampton, MA). Control experiments included the titration of polyphenol solution into the model wine and were subtracted from titration experiments.

\section{Results and discussion}

\subsection{Characterization of the yeast protein extract}

Total Nitrogen accounted for $6.0 \pm 0.7 \%$ of the YPE powder dry weight. Nitrogen in yeast is related to amino acids, peptides and proteins but also to nucleic acids. Assuming that the latter can be neglected, this content would indicate the presence of about $37.5 \%$ amino acids/peptides/proteins (obtained by multiplying the total nitrogen by the factor 6.25 ). Total amino acids represented $33.5 \%$ of YPE dry weight, which is close to total nitrogen (supplementary data S1). Free amino acids accounted for about half of these total amino acids. The studied YPE was not fully soluble upon rehydration. The insoluble part (13\% dry weight) was removed by centrifugation and disregarded in further experiments. The soluble part $(87 \%)$ was further analysed in terms of nitrogen and carbohydrate components (Fig. 1), and fractionated by ultrafiltration to distinguish between proteins or polysaccharides (molecular 
weight $>10 \mathrm{kDa}$ ) and low molecular weight compounds (molecular weight $<10 \mathrm{kDa}$ ). High molecular weight compounds (> $10 \mathrm{kDa}$ ) only represented $20 \% \mathrm{w} / \mathrm{w}$ of the total. Total nitrogen, glucose and mannose accounted for 7, 18 and $16 \% \mathrm{w} / \mathrm{w}$ of them, respectively. This indicated the presence of about $8.8 \%$ proteins with MW higher than $10 \mathrm{kDa}$ in the YPE soluble, and of glucan and mannoprotein polymers/copolymers (6.8\%). 1D-SDS-PAGE analysis (Fig. 1B) showed ten different protein bands with molecular weights ranging from 14 to $66 \mathrm{kDa}$. Eight of the bands corresponded to proteins with molecular weight greater than $20 \mathrm{kDa}$. Major components in YPE, i.e. $80 \% \mathrm{w} / \mathrm{w}$, were low molecular weight compounds $(<10 \mathrm{kDa})$. The level of total nitrogen corresponded to about $21 \% \mathrm{w} / \mathrm{w}$ free amino acids and small peptides, in accordance with the analysis of free amino acids (supplementary data S1). Oligosaccharides $(18 \% \mathrm{w} / \mathrm{w})$ were mostly composed of glucose. These results strongly suggested protease and $\beta$-glucanase activities during the industrial process applied to obtain the YPE. The industrial conditions used to obtain this YPE did not prevent protein autolysis and this latter did not match the OIV standard, i.e. at least $25 \%$ proteins with molecular weight higher than $15 \mathrm{kDa}$ (OIV-Oeno 452-2012). YPE previously described in the literature and tested as fining agents did not correspond either to the OIV specifications (Charpentier et al., 2006; Iturmendi et al., 2010; Lochbühler et al., 2014).

\subsection{Polyphenol fractions}

Analyses of the polyphenol fractions used for interaction studies are summarized in Table 1. Grape skin tannins (GST) presented a high mean degree of polymerization (mDP 27) and the fraction was devoid of monomers and oligomers. The high conversion yield of the depolymerization reaction indicated that tannins in this fraction were mostly native structures. The wine pool WP was composed of monomers (free anthocyanins and their derivatives, cinnamic acids, flavonols, flavanol monomers), tannins and of a large amount of derived 
structures, as evidenced by the low yield of the depolymerization reaction. These derived structures are formed during winemaking and aging due to the chemical reactivity of polyphenols and mainly involve anthocyanins and tannins in red wines. This chemical reactivity leads to the formation of a huge diversity of so-called derived tannins and pigments, including oligomeric and polymeric pigments formed through reactions between anthocyanins and tannins (Fulcrand, Duenas, Salas \& Cheynier, 2006; Cheynier et al., 2006, Aron \& Kennedy, 2007). These changes result in a decrease in percent conversion yield in depolymerization reactions used for the analysis of tannins (Poncet-Legrand et al., 2010; Vernhet et al., 2011; Bindon, Bacic \& Kennedy, 2012), related to the formation of new covalent bonds between units resistant to acid-catalyzed cleavage. In that case, the information obtained does not reflect the real average composition or $\mathrm{mDP}$ of tannins and must be considered with caution.

WP was further fractionated in two fractions. The first one contained monomers and oligomers (native and derived structures). It accounted for $63 \%$ of the initial WP on a dry weight basis. The depolymerization yield was $8.5 \%$ and analysis indicated an $\mathrm{mDP}$ of 2.5 (data not shown). This fraction was disregarded in further experiments. The second fraction, named WT, was devoid of monomers and oligomers and represented $37 \% \mathrm{w} / \mathrm{w}$ of the tannins in the initial WP. The yield of the depolymerization reaction, $42.8 \%$, was twice that obtained with the whole WP but still characteristic of chemically modified tannins. The UV-visible spectrum of WT in the model wine showed absorption in the visible range with two maximums at 460 and $520 \mathrm{~nm}$, typical of oxidation products and tannin-bound anthocyanins.

\subsection{Binding experiments between YPE and polyphenols.}


Results of binding experiments between polyphenols (GST, WP or WT) and YPE are reported

Fig. 2A. YPE concentration was set at $1.74 \mathrm{~g} . \mathrm{L}^{-1}$, which corresponded to $154 \mathrm{mg} . \mathrm{L}^{-1}$ yeast proteins. Polyphenol concentrations were varied between 0.25 and $2 \mathrm{~g} . \mathrm{L}^{-1}$. Interactions between initially soluble components may result in the formation of complexes, involving only few constituents, or of larger aggregates. Depending on their structure and surface properties (charge and hydrophilic/hydrophobic character) these aggregates may reach a finite submicronic size at which they remain metastable or, on the contrary, keep on growing to form large precipitates that sediment spontaneously. Centrifugation $(15000 \mathrm{~g}, 15 \mathrm{~min}$.) was used to remove polypheno1/YPE aggregates/precipitates and determine the amount involved. Thus, the results indicated whether or not aggregates with size and density compatible with their separation in these conditions were formed, but they did not indicate spontaneous precipitation and sedimentation. The reversibility of the interactions was measured at different polyphenol concentrations (Fig. 2B).

Very different behaviors were observed between the studied phenolic fractions with regard to their interactions with YPE components. Interactions between GST and YPE led to the aggregation/precipitation of a higher amount of polyphenols than those involving wine polyphenols (WP and WT) and YPE: at an initial polyphenol concentration of 2 g.L $\mathrm{L}^{-1}$, removed polyphenols represented 17, 2.5 and 8\% for GST, WP and WT respectively (Fig. 2A). Besides, absorbency measurements performed with WP showed color intensity losses: the color intensity of WP at a concentration of 1 g.L. $\mathrm{L}^{-1}$ decreased from 1.91 to 1.71 at after interaction with YPE, and at 2 g.L $\mathrm{L}^{-1}$ from 5.23 to 5.01. This indicated that oligomeric and/or polymeric derived pigments were involved in the interactions between wine polyphenols and YPE. Interactions between YPE and GST or WT were found to be mostly irreversible (Fig. 2 B). This irreversibility is typical of the formation of multiple bonds. Multiple bonding is expected with tannins (Cartalade \& Vernhet, 2006; Charlton et al., 2002) and especially those of higher 
mDP. By contrast, a significantly higher reversibility was found with the WP. This indicated that low molecular weight structures in WP (polyphenol monomers and oligomers, $63 \% \mathrm{w} / \mathrm{w}$ ) were involved in interactions with YPE and competed with higher molecular weight polymers (WT, 37\% of the polyphenols in WP). HPLC analyses performed on the supernatants recovered after interaction experiments at 1 and 2 g.L $\mathrm{L}^{-1}$ showed that polyphenols monomers (free anthocyanins and their derivatives, cinnamic acids, flavonols, flavanol monomers, ...) were not involved (results not shown). Competition between low and high molecular weight structures for interaction with YPE is thus related to oligomers. 1D-SDS-PAGE analyses performed on supernatants after binding experiments indicated that yeast proteins were removed from the lowest tested concentration with GST $\left(0.25\right.$ g.L $\left.\mathrm{L}^{-1}\right)$, whereas major proteins were still detectable in the supernatant up to concentrations of 0.75 g. $\mathrm{L}^{-1}$ with $\mathbf{W T}$ and 1.5 g. $\mathrm{L}^{-1}$ with WP (Supplementary data S2). It is important to note that the presence of residual proteins in the supernatants of WP and WT does not necessarily mean that they were not involved in interactions with polyphenols. It indicates that if interactions occurred, they did not result in aggregates liable to be removed in the applied centrifugation conditions. Polyphenols fractions could thus be ranked by decreasing order with regards to their ability to form polyphenols/protein large aggregates or precipitates, as follow: GST $>$ WT $>$ WP.

Dynamic Light Scattering and Isothermal Titration Calorimetry experiments were performed to further identify the origin of the differences observed between the studied polyphenol fractions in their interactions with YPE. Although interactions are expected to involve especially yeast proteins, YPE also contained non-negligible amount of mannoproteins (about $56 \mathrm{mg} . \mathrm{L}^{-1}$ ) and $\beta$ glucans $\left(62 \mathrm{mg} . \mathrm{L}^{-1}\right)$. The ability of mannoproteins to bind red wine tannins has been reported (Rowe et al., 2010, Mekoue et al., 2015b) and there is no information concerning $\beta$-glucan interactions with tannins. Commercial MPs and a model $\beta$-glucan, Laminarin, were used to 
check the potential impact of these polysaccharides and compare their interactions with those of YPE.

3.2. Dynamic light scattering study of the aggregation between YPE, mannoproteins, $\beta$-glucan and polyphenols.

Aggregation between YPE, mannoproteins (MPs) or the $\beta$-glucan and GST, WP or WT was followed during 24 hours by DLS. The results shown in Fig. 3 represent the Intensity scattered $\left(\mathrm{I}_{\mathrm{S}}\right)$ and the average hydrodynamic diameters of aggregates $\left(\mathrm{D}_{\mathrm{H}}\right)$ after $15 \mathrm{~min}$ and 24 h. In Fig. 3 are given $I_{S}$ of the controls, i.e. of the solutions considered separately ( $\mathrm{I}_{\mathrm{S}}-\mathrm{YPE}, \mathrm{MPs}$ or $\beta$ glucan and $\mathrm{I}_{\mathrm{S}-\text { Polyphenols }}$ ), the sum of these intensities ( $\mathrm{I}_{\mathrm{S}-\mathrm{YPE} \text {,MPs or } \beta \text {-glucan }}+\mathrm{I}_{\mathrm{S}-\text {-Polyphenols, }}$, calculated),

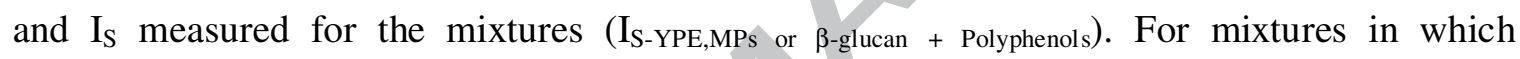
components behave independently, the sum of the intensities scattered by the controls equals that of the mixture. If aggregates form, the intensity scattered by the mixture will be higher as long as aggregation does not result in sedimentation.

Measurements performed on YPE alone (before adding polyphenols) showed the presence of colloidal particles with an average hydrodynamic diameter $D_{H}$ of about $150 \mathrm{~nm}$. These particles formed insoluble residues that were not removed by the centrifugation procedure adopted to separate YPE from the insoluble fraction (15000 g, $15 \mathrm{~min})$. The nature of these residual colloids, as well as that of the insoluble fraction of YPE, was not elucidated here. They formed a stable dispersion in water and remained dispersed when the concentrated YPE was diluted in the model wine-like solution for interaction experiments. YPE concentration was set first at a concentration of 0.4 g.L ${ }^{-1}$. The addition of GST $\left(0.4\right.$ g.L $\left.{ }^{-1}\right)$ led to the very fast formation of highly polydisperse micron-sized aggregates. After $5 \mathrm{~h}$ of contact, spontaneous sedimentation of these aggregates was observed, characterized by a decrease of 
both the scattering intensity $\mathrm{I}_{\mathrm{S}}$ and the measured $\mathrm{D}_{\mathrm{H}}$. The same experiments were repeated with WP and WT: in both cases an immediate increase of $\mathrm{I}_{\mathrm{S}}$ was observed by comparison to the controls, followed by stabilization. This indicated interactions between YPE components and polyphenols in WP and WT. These interactions were associated with a slight increase of $\mathrm{D}_{\mathrm{H}}$ by comparison to that of YPE residual colloids but no enlarged aggregation and precipitation was observed. Increasing YPE and WT or WP concentrations to values similar to those used in binding experiments (YPE: 1.74 g.L $\mathrm{L}^{-1}$; WT and WP: 2 g.L $\mathrm{L}^{-1}$ ) did not lead to an enlarged aggregation (results non shown). Only a slight increase of the scattering intensity by comparison to the YPE control was observed with WP (around 20\%), along with a small increase of the aggregate $\mathrm{D}_{\mathrm{H}}$ (from 150 to about $200 \mathrm{~nm}$ ). With WT, the scattered intensity was doubled and the increase in $\mathrm{D}_{\mathrm{H}}$ was higher (about $300 \mathrm{~nm}$ ). However, both dispersions remained stable during the experiment duration $(24 \mathrm{~h})$.

These results accounted for the differences observed between GST, WT and WP in binding experiments and indicated different interaction mechanisms and consequences at a colloidal level. Binding and spontaneous precipitation of proteins by condensed tannins are influenced by several factors, among which are the mDP of tannins (Harbertson, Kilmister, Kelm, \& Downey, 2014; Zeller et al., 2015), the structure and the isoelectric point of the protein (Lorenz et al., 2014; Zeller et al., 2015), the $\mathrm{pH}$ of the medium and the ratio between proteins and tannins. It has been shown that high $\mathrm{mDP}$ condensed tannins $(\mathrm{mDP}=18)$ are more effective to precipitate proteins than medium mDP (mDP=9) ones (Lorenz et al., 2014): the amount of tannins needed to precipitate proteins is lower. On the other hand, tannin amount precipitated by BSA increases with tannin $\mathrm{mDP}$ (for $\mathrm{mDP}$ between 4 to 8 ) (Harbertson et al., 2014). This is attributed to the fact that increasing the polymer size increases the number of interaction sites and thus the opportunities for tannins for cross-linking between proteins and form larger aggregates prone to precipitation. Although the mDP values obtained from analyses 
do not represent the real ones for WP and WT tannins, their lower ability to precipitate yeast proteins could first be related to the fact that this mDP is lower than that of skin tannins, and lower for tannins in WP than that of WT. The fact that no spontaneous precipitation occurs even with WT can also suggest an impact of the structural changes undergone by condensed tannins in wine by comparison to native structures. Generally, the length of polymers, their degree of branching and the distribution and nature of interaction sites are of fundamental importance in their interactions. Tannin changes during winemaking and ageing are still poorly understood and hardly accessible to analyses. However there is some evidence that these changes may affect: (i) their mDP and conformation (linear versus branched polymers) and thus accessibility to interaction sites; ii) the nature of these sites and their hydrophobic/hydrophilic character (Poncet-Legrand et al., 2010; McRae, Falconer \& Kennedy, 2010). Among these changes, reactions between anthocyanins in tannins result in the incorporation of positively charged subunits and of glucose residues in derived structures. Such changes likely modify mechanisms involved in tannin interactions with YPE components and their consequences in terms of structure and stability of the aggregate formed.

Experiments were performed with mannoproteins and the $\beta$-glucan (laminarin) at the same concentrations used with YPE (Fig.3B and C). The scattering intensities of the mannoproteins and of the polyphenols solutions were very low. Mixing these solutions resulted in an abrupt rise of the scattering intensity to values around 20 to 25 times higher than the sum of the individual solutions. This clearly indicated interactions between the MPs and polyphenols, leading to the formation of colloidal aggregates. These interactions may involve tannins as well as anthocyanins and derived pigments (Morata et al., 2003; Rowe et al., 2010; Alcade-Eon et al., 2014; Mekoue et al., 2015a). Neither $\mathrm{I}_{\mathrm{S}}$ nor $\mathrm{D}_{\mathrm{H}}$ of the aggregates significantly evolve during the experiments for GST $\left(\mathrm{D}_{\mathrm{H}}\right.$ around $\left.600 \mathrm{~nm}\right)$ and $\mathbf{W P}\left(\mathrm{D}_{\mathrm{H}}\right.$ around $270 \mathrm{~nm})$. Aggregation kinetics were slower with WT since both $\mathrm{D}_{\mathrm{H}}$ and $\mathrm{I}_{\mathrm{S}}$ increased during the 
experiment duration, to stabilization. As for YPE, the different average sizes and kinetics indicated different aggregation mechanisms and structure of the aggregates depending on the polyphenol structures. Especially the differences observed between WP and WT suggested a competition between monomers/oligomers and higher molecular weight tannins in the interaction. However in all cases, interactions between polyphenols and mannoproteins resulted in the formation of stable colloidal dispersions. Neither precipitation nor visible haze was observed in the samples after several days, even with GST. If interactions with tannins are related to the protein moiety (10\% of the mannoproteins), the polysaccharide part in MPs thus strongly prevented the precipitation of the aggregates. The effect of protein glycosylation on tannin-protein precipitation had already been evidenced with salivary proline-rich proteins (Pascal, Poncet-Legrand, Cabane \& Vernhet 2008). The glycosyl moiety of mannoproteins is strongly hydrophilic and carries a negative charge (Vernhet, Pellerin, Prieur, Osmianski \& Moutounet, 1995). This glycosyl moiety may create steric hindrance that limits the extent of bridging by tannins and may remain exposed at the outer surface of the aggregates, preventing them from continuing to grow and precipitate. In addition, the negative charge may favour interactions between this glycosyl moiety and positively charged pigments in WP and WT. With the $\beta$-glucan, which is a true polysaccharide (no protein moiety), the scattering intensity of the mixture $\left(\mathrm{I}_{\mathrm{S}-(\beta-\mathrm{glucan}+\mathrm{PP})}\right)$ remained similar to the sum of their own scattering intensity $\left(\mathrm{I}_{\mathrm{S}-\beta-}\right.$ glucan $\left.+I_{S-P P}\right)$, indicating there were no interactions leading to the formation of aggregates.

As yeast proteins, residual MPs in YPE may thus be involved in interactions with polyphenols and contribute to their removal by centrifugation during binding experiments. It must be however kept in mind that their concentration in YPE is three time lower than the one of proteins, and about 7 times lower than in DLS experiments (56 mg. $\mathrm{L}^{-1}$ instead of $\left.400 \mathrm{mg} \cdot \mathrm{L}^{-1}\right)$. 


\subsection{Isothermal Titration Calorimetry}

ITC experiments were performed to further compare interactions between YPE, mannoproteins or $\beta$-glucan and polyphenols. Although ITC is a powerful technique to study the thermodynamics of protein-ligand interactions, calorimetric isotherms must be interpreted carefully (Jelesarov \& Bosshard, 1999), especially when studying non-specific interactions between tannins and proteins or other macromolecules (Kilmister, Faulkner, Downey, Darby \& Falconer, 2016). With proteins, changes in enthalpy may arise from a combination of several phenomena: binding of tannins to proteins, aggregation (Frazier, Papadopoulou, MuellerHarvey, \& Kissoon, Green, 2003) of the complexes thus formed, conformation changes of the tannin and/or the protein (Pascal et al., 2007), self-association/dissociation of tannins and/or proteins. Nevertheless, in several previous works, the interactions between polyphenols and proteins were described as the association of hydrophobic interaction and hydrogen bounding, depending on tannins and protein structure (Frazier et al., 2003; Poncet-Legrand, Gautier, Cheynier, \& Imberty, 2007; Prigent et al., 2009; McRae et al., 2010; Kilmister et al., 2016).

ITC results of the polyphenols fractions (GST, WT and WP) titrated into YPE or MPs at $25^{\circ} \mathrm{C}$ are shown Fig.4. Titration signals (Fig. 4 b and $4 \mathbf{d}$ ) were typical of enthalpy-driven protein-ligand interactions, with a more or less rapid decrease of exothermic peaks upon polyphenol addition. As the polyphenol concentration increased, the number of available binding sites decreased; hence, the enthalpy changes associated with binding decreased. From the titration curves the change in enthalpy $\Delta \mathrm{H}$ was calculated from the area under each peak and was expressed as a function of mass ratio (polyphenols/YPE or polyphenols/MPs) instead of molar ratio (Fig. 4c and 4e): because of the presence of different molecular weights and structures in the YPE, MPs and polyphenol solutions, molar concentrations were not calculable. 
Likewise, association constants, thermodynamics and stoichiometry parameters were not calculated.

The heats of interaction and the mass ratio for which the titration into YPE could be considered as complete differed depending on the considered polyphenol fraction. The shape of the initial part of the binding curves suggested a strong affinity between GST or WT and YPE, and contrarily a low affinity between WP and YPE. The binding sites present in YPE were saturated at a mass ratio of about 0.05 with GST, instead of 0.2 with WT and WP. Changes in enthalpy $(\Delta \mathrm{H})$ observed at a given temperature result from the balance between exothermic $(\mathrm{H}-$ bonding) and endothermic (hydrophobic interactions) binding interactions. Additional experiments were then performed with GST and WP at $10^{\circ} \mathrm{C}$ (Fig. 5) to study the influence of hydrogen bonding (exothermic binding interaction, negative $\Delta \mathrm{H}$ ) and hydrophobic interactions (endothermic, positive $\Delta \mathrm{H}$ ). Increasing the temperature increases hydrophobic interactions and thus the strength of the endothermic component. The higher $\Delta \mathrm{H}$ observed at $10^{\circ} \mathrm{C}$ by comparison to $25^{\circ} \mathrm{C}$ with GST and WP are consistent with the association of hydrogen bonding and hydrophobic interactions between YPE components and tannins or wine polyphenols, in accordance with previous data (McRae et al, 2010; Kilmister et al., 2016). At $25^{\circ} \mathrm{C}$, the heat changes observed during the titration of WT into YPE were higher than those observed with GST, and about 2-fold higher than those observed with WP at the same concentration. The higher negative $\Delta \mathrm{H}$ found for WT by comparison to GST may reflect different ratios between hydrogen bonding and hydrophobic interactions in their binding to YPE components. The much lower $\Delta \mathrm{H}$ values found for WP by comparison to WT suggest a competition between small oligomers and higher molecular weight tannins when present together in solution, which is in agreement with the higher reversibility observed in binding experiments (Fig. 2). Indeed, previous ITC study of the interactions between procyanidins of various mean degrees of polymerization and globular proteins (Prigent et al., 2009) showed 
only weak interactions with epicatechin and tannin dimers, whereas strong affinities were observed for high mDP tannins. In accordance with this, changes in enthalpy and association constant found for the binding of purified tannins to bovine serum albumin were shown to increase with tannin mDP up to hexamer, and then to reach a plateau for heptamer and octamer (Kilmister et al., 2016).

The shape of the initial part of the binding isotherm and the low $\Delta \mathrm{H}$ at $25^{\circ} \mathrm{C}$ indicated a much lower affinity between GST and mannoproteins than between GST and YPE (Fig. 4d and $4 \mathrm{e})$. The saturation was reached for a mass ratio of $0.02 . \Delta \mathrm{H}$ at $25^{\circ} \mathrm{C}$ were even lower with mannoproteins and WT and nil with mannoproteins and WP. Additional experiments performed at $10{ }^{\circ} \mathrm{C}$ (Fig. 5) for GST and WP showed an increase of the heat exchanged during interactions between mannoproteins and grape skin tannins or polyphenols in WP. This suggested that endothermic hydrophobic interactions occur simultaneously with exothermic hydrogen bonding in polyphenols interactions with mannoproteins, as observed with YPE.

With the $\beta$-glucan, the titrations were different (supplementary data S3). With GST, the $\beta$-glucan concentration was increased to 20 g. $\mathrm{L}^{-1}$ to allow measurements at 25 and $10^{\circ} \mathrm{C}$, and the enthalpy changes remained very low. Results showed initial exothermic interactions $(\Delta \mathrm{H}<0)$ at $25^{\circ} \mathrm{C}$, followed by endothermic interactions $(\Delta \mathrm{H}>0)$. At $10^{\circ} \mathrm{C}$, interactions were exothermic. This may indicate the association of hydrophobic interactions and H-bonding in GST interactions with $\beta$-glucans. However, saturation was reached at a very low mass ratio by comparison to YPE and mannoproteins, indicating only very few interaction sites. Changes in $\Delta \mathrm{H}$ observed with WP at 25 and $10{ }^{\circ} \mathrm{C}$ were also positive but closed to its dilution in the winelike solution (Supplementary data S3). One the whole, these results indicated negligible interactions between the $\beta$-glucan and polyphenols, in accordance with that observed by DLS.

Considering the whole ITC data, it can be concluded that for all polyphenol fractions, interactions with mannoproteins were much weaker than those observed with YPE and 
negligible with the $\beta$-glucan. This is in agreement with previous ITC studies of the interactions between different plant cell wall or wine pectic polysaccharides and apple tannins of different mDP (9 and 30) (Le Bourvellec, Watrelot, Ginies, Imberty, \& Renard, 2012; Watrelot, Le Bourvellec, Imberty, \& Renard, 2014). At $25{ }^{\circ} \mathrm{C}$, much smaller negative $\Delta \mathrm{H}$ values were observed during the binding of tannin with polysaccharides (apple pectin and wine rhamnogalacturonans II and arabinogalactan-proteins) than that observed in the literature between tannins and proteins or poly-L-proline. Beside, both mDP9 and 30 tannins exhibited very low affinities for rhamnogalacturonans II and the two studied arabinogalactan-proteins (AGP0 - protein moiety $3.6 \%$ and AGP4 - protein moiety $0.8 \%$ ).

\section{Conclusion.}

The results described above led to different main conclusions. Interactions between yeast proteins and tannins (grape and wine tannins) are higher than those observed with mannoproteins. Negligible interactions were observed between laminarin (model $\beta$-glucan) and tannins, either through ITC or DLS experiments. This is in accordance with previous results obtained with whole dead or inactivated yeast and yeast cell walls (Mekoue Nguela et al., $2015 \mathrm{a}$ and b). In these experiments, strong differences were observed between cell walls (mannoproteins and $\beta$-glucans) and whole yeasts in their interactions with grape and wine

tannins. The adsorbed amount was much higher with whole cells than with purified cell walls, due to strong interactions with yeast cytoplasmic constituents (a priori proteins), demonstrated later by microscopic techniques. Microscopy also revealed interactions between mannoproteins in the cell walls and tannins, but not with $\beta$-glucans. The reversibility of this adsorption was also much smaller with whole cells than with cell walls. When dealing with polymers, 
reversibility reflects the formation of multiple bonds and this indicated reduced numbers of interaction sites between tannins and mannoproteins than between tannins and yeast proteins, in accordance with that found in solution by ITC.

Another conclusion, also in agreement with results obtained with whole yeasts and yeast cell walls and previous literature data is that the chemical structure of tannins and their structural changes during winemaking and aging plays a decisive part in their interactions with yeast proteins and mannoproteins. The present results indicated a competition between wine polyphenols oligomers and higher molecular weight tannins, and wine tannins exhibited a different behavior than grape skin tannins. Binding experiments, ITC and DLS investigations not only showed the strong impact of tannin structure on their interactions with yeast proteins but also on the structure and stability of the aggregate formed. The addition of GST to YPE led to enlarged aggregation followed by sedimentation, whereas WT and WP led to the formation of metastable aggregates that did not settle spontaneously. The different aspects of fining have not been studied in the context of this work. Nevertheless, the absence of spontaneous precipitation after interactions between proteins in the YPE and wine polyphenols (WP and WT) raises the question of their use as fining agent for wine clarification. Present experiments were performed in a model wine and with tannins purified from a given red wine. The impact of wine composition (tannins structure, ethanol, ionic strength, presence of co-solutes...) and of the physico-chemical properties of yeast protein on these interactions and on their consequences at a colloidal level will need to be further investigated. In solution, interactions between mannoproteins and tannins led to the formation of colloidal aggregates that retained a finite size and remained stable. This was attributed to their glycosyl moiety that may (i) prevent multiple bridging between tannins and their protein part and, (ii) form a hydrophilic and negatively charged shell around aggregates that stop their growth. As with yeast proteins, further works will be needed to better identify the mechanisms involved (competition between 
polyphenolic structures in complex media such as wine, resulting structural features) and their impact on wine color stability and mouthfeel.

\section{Abbreviation used}

DLS: dynamic light scattering

GST: grape skin tannins

WP: wine pool

WT: wine tannins

YPE: yeast protein extract

$\mathrm{D}_{\mathrm{H}:}$ average hydrodynamic diameter

$\mathrm{I}_{\mathrm{S}}$ : intensity scattered

\section{Acknowledgements}

The authors thank Jean-Paul Mazauric, Jean-Marc Souquet, Stéphanie Carrillo and Jean-Marc Brioullet for their precious help during polyphenol purification and analysis; Stéphanie Roi for her precious help in the realization of interaction experiments and François-Xavier Sauvage and Patrick Chemardin for their precious help in SDS-PAGE protein analysis. 


\section{Litterature cited}

Albersheim, P., Nevins, D. J., English, P. D., \& Karr, A. (1967). A method for the analysis of sugars in plant cell wall polysaccharides by gas-liquid chromatography. Carbohydrate Research., 5, 240-245.

Alcalde-Eon, C., García-Estévez, I., Puente, V., Rivas-Gonzalo, J. C., \& Escribano-Bailón, M. T. (2014). Color stabilization of red wines. A chemical and colloidal approach. Journal of Agricultural and Food Chemistry, 62(29), 6984-6994.

Aron, P. M., \& Kennedy, J. A. (2007). Compositional investigation of phenolic polymers isolated from Vitis vinifera L. Cv. Pinot Noir during fermentation. Journal of Agricultural and Food Chemistry, 55(14), 5670-80.

Bindon, K. A., Bacic, A., \& Kennedy, J. A. (2012). Tissue-Specific and Developmental Modifications of Grape Cell Walls Influence the Adsorption of Proanthocyanidins. Journal of Agricultural and Food Chemistry, 60, 9249-9260.

Cartalade, D., \& Vernhet, A. (2006). Polar interactions in flavan-3-ol adsorption on solid surfaces. Journal of Agricultural and Food Chemistry, 54(8), 3086-3094.

Charlton, A. J., Baxter, N. J., Lokman Khan, M., A.J.G., M., Haslam, E., Davies, A. P., \& Williamson, M. P. (2002). Polyphenol/peptide binding and precipitation. J. Agric. Food Chem., 50, 1593-1601.

Charpentier, C., Caillet, M., \& Feuillat, M. (2006). Essais de collage de moûts blancs et de vins rouges avec un extrait proteique levurien: comparaison avec les colles traditionnelles. Revue Des Oenologues, 120, 47-50.

Cheynier, V., Dueñas-Paton, M., Salas, E., Maury, C., Souquet, J.-M., Sarni-Manchado, P., \& Fulcrand, H. (2006). Structure and properties of wine pigments and tannins. American Journal of Enology and Viticulture, 57(3), 298-305.

Del Barrio-Galán, R., Pérez-Magariño, S., Ortega-Heras, M., \& Guadalupe, Z. (2012). Polysaccharide characterization of commercial dry yeast preparations and their effect on white and red wine composition. Lwt-Food Science and Technology, 48(2), 215-223

Dallies, N., François, J., \& Paquet, V. (1998). A new method for quantitative determination of polysaccharides in the yeast cell wall. Application to the cell wall defective mutants of Saccharomyces cerevisiae. Yeast (Chichester, England), 14(14), 1297-306.

Ducasse, M.-A., Canal-Llauberes, R.-M., de Lumley, M., Williams, P., Souquet, J.-M., Fulcrand, H., ... Cheynier, V. (2010). Effect of macerating enzyme treatment on the polyphenol and polysaccharide composition of red wines. Food Chemistry, 118(2), 369-376.

Escot, S., Feuillat, M., Dulau, L., \& Charpentier, C. (2001). Release of polysaccharides by yeasts and the influence of released polysaccharides on colour stability and wine astringency. Australian Journal of Grape and Wine Research, 7, 153-159. 
Fulcrand H, Duenas M, Salas E, Cheynier V (2006). Phenolic reactions during winemaking and aging. American Journal of Enology and Viticulture 57: 289-297.

Frazier, R. A., Papadopoulou, A., Mueller-Harvey, I., \& Kissoon, D.; Green, R. J. (2003). Probing protein-tannin interactions by isothermal titration microcalorimetry. J. Agric. Food Chem., 51, 5189-5195.

Granato, T. M., Piano, F., Nasi, A., Ferranti, P., Iametti, S., \& Bonomi, F. (2010). Molecular basis of the interaction between proteins of plant origin and proanthocyanidins in a model wine system. Journal of Agricultural and Food Chemistry, 58(22), 11969-11976.

Guadalupe, Z., Martínez, L., \& Ayestarán, B. (2010). Yeast Mannoproteins in Red Winemaking : Effect on Polysaccharide , Polyphenolic , and Color Composition, 2, 191-200.

Harbertson, J. F., Kilmister, R. L., Kelm, M. A., \& Downey, M. O. (2014). Impact of condensed tannin size as individual and mixed polymers on bovine serum albumin precipitation. Food Chemistry, 160, 16-21.

Iturmendi, N., Durán, D., Marín-Arroyo, M. R., \& Marin-Arroyo, R. (2010). Fining of red wines with gluten or yeast extract protein. International Journal of Food Science \& Technology, 45(2), 200-207.

Jelesarov, I., \& Bosshard, H. R. (1999). Isothermal titration calorimetry and differential scanning calorimetry as complementary tools to investigate the energetics of biomolecular recognition. Journal of Molecular Recognition: JMR, 12(1), 3-18.

Kilmister, R. L., Faulkner, P., Downey, M. O., Darby, S. J., \& Falconer, R. J. (2016). The complexity of condensed tannin binding to bovine serum albumin - An isothermal titration calorimetry study. Food Chemistry, 190, 173-178.

Lochbühler, B., Manteau, S., Morge, C., Caillet, M.-M., Charpentier, C., Schnell, S., ... Rauhut, D. (2014). Yeast protein extracts: an alternative fining agent for red wines. Eur Food Res Technol, 240(4), 689-699.

Loira, I., Vejarano, R., Morata, A., Ricardo-da-Silva, J. M., Laureano, O., González, M. C., \& Suárez-Lepe, J. A. (2013). Effect of Saccharomyces strains on the quality of red wines aged on lees. Food Chemistry, 139(1-4), 1044-51.

Lorenz, M. M., Alkhafadji, L., Stringano, E., Nilsson, S., Mueller-Harvey, I., \& Udén, P. (2014). Relationship between condensed tannin structures and their ability to precipitate feed proteins in the rumen. Journal of the Science of Food and Agriculture, 94(5), 963-968.

Mazauric, J.-P., \& Salmon, J.-M. (2005). Interactions between Yeast Lees and Wine Polyphenols during Simulation of Wine Aging: I. Analysis of Remnant Polyphenolic Compounds in the Resulting Wines. Journal of Agricultural and Food Chemistry, 53(14), $5647-5653$.

McRae, J. M., Falconer, R. J., \& Kennedy, J. A. (2010). Thermodynamics of grape and wine tannin interaction with polyproline: implications for red wine astringency. Journal of Agricultural and Food Chemistry, 58(23), 12510-8. 
Mekoue Nguela, J., Sieczkowski, N., Roi, S., \& Vernhet, A. (2015a). Sorption of grape proanthocyanidins and wine polyphenols by yeasts, inactivated yeasts, and yeast cell walls. Journal of Agricultural and Food Chemistry, 63(2), 660-70.

Mekoue Nguela, J., Vernhet, A., Sieczkowski, N., \& Brillouet, J.-M. (2015b). Interactions of Condensed Tannins with Saccharomyces cerevisiae Yeast Cells and Cell Walls: Tannin Location by Microscopy. J. Agric. Food Chem., In Press.

Morata, A., Gómez-Cordovés, M. C., Suberviola, J., Bartolomé, B., Colomo, B., \& Suárez, J. A. (2003). Adsorption of anthocyanins by yeast cell walls during the fermentation of red wines. Journal of Agricultural and Food Chemistry, 51(14), 4084-4088.

Pascal, C., Poncet-Legrand, C., Imberty, A., Gautier, C., Sarni-Manchado, P., Cheynier, V., \& Vernhet, A. (2007). Interactions between a non glycosylated human proline-rich protein and flavan-3-ols are affected by protein concentration and polyphenol/protein ratio. J. Agric. Food Chem., 55, 4895-4901.

Pascal, C., Poncet-Legrand, C., Cabane, B., \& Vernhet, A. (2008). Aggregation of proline-rich protein induced by epigallocatechin gallate and condensed tannins: effect of protein glycosylation. Journal of Agriculture and Food Chemistry, 56, 6724-6732.

Palomero, F., Benito, S., Morata, A., Tesfaye, W., González, M. C., \& Suárez-Lepe, J. A. (2009). Effect on the autolysis process and the colouring matter of several commercial preparations with $\beta$-glucanase action in red winemaking. European Food Research and Technology, 229(4), 585-592.

Poncet-Legrand, C., Gautier, C., Cheynier, V., \& Imberty, A. (2007). Interactions between flavan-3-ols and poly(L-proline) studied by isothermal titration calorimetry: Effect of the tannin structure. Journal of Agricultural and Food Chemistry, 55(22), 9235-9240.

Poncet-Legrand, C., Cabane, B., Bautista-Ortín, A.-B., Carrillo, S., Fulcrand, H., Pérez, J., \& Vernhet, A. (2010). Tannin Oxidation: Intra- versus Intermolecular Reactions. Biomacromolecules, 11(9), 2376-2386.

Pozo-Bayón, Á. M., Andújar-Ortiz, I., \& Moreno-Arribas, M. V. (2009). Scientific evidences beyond the application of inactive dry yeast preparations in winemaking. Food Research International, 42(7), 754-761.

Prigent, S. V. E., Voragen, A. G. J., van Koningsveld, G. A., Baron, A., Renard, C. M. G. C., \& Gruppen, H. (2009). Interactions between globular proteins and procyanidins of different degrees of polymerization. Journal of Dairy Science, 92(12), 5843-53.

Prieur, C., Rigaud, J., Cheynier, V., \& Moutounet, M. (1994). Oligomeric and polymeric procyanidins from grape seeds. Phytochemistry, 36(3), 781-784.

Rodrigues, A., Ricardo-da-silva, J. M., Lucas, C., \& Laureano, O. (2012). Effect of commercial mannoproteins on wine colour and tannins stability. Food Chemistry, 131(3), 907-914. 
Roumeas, L., Aouf, C., Dubreucq, E., \& Fulcrand, H. (2013). Depolymerisation of condensed tannins in ethanol as a gateway to biosourced phenolic synthons. Green Chemistry, 15(11), 3268-3275.

Rowe, J. D., Harbertson, J. F., Osborne, J. P., Freitag, M., Lim, J., \& Bakalinsky, A. T. (2010). Systematic identification of yeast proteins extracted into model wine during aging on the yeast lees. Journal of Agricultural and Food Chemistry, 58(4), 2337-46.

Vernhet, A., Pellerin, P., Prieur, C., Osmianski, J. \& Moutounet, M. (1995). Charge properties of some grape ens wine polysaccharide and polyphenolic fractions. American Journal of Enology and Viticulture, 47 (1), 25-30.

Vernhet, A., Dubascoux, S., Cabane, B., Fulcrand, H., Dubreucq, E., \& Poncet-Legrand, C. (2011). Characterization of oxidized tannins: comparison of depolymerization methods, asymmetric flow field-flow fractionation and small-angle X-ray scattering. Analytical and Bioanalytical Chemistry, 401(5), 1559-69.

Wiederhold, E., Veenhoff, L. M., Poolman, B., \& Slotboom, D. J. (2010). Proteomics of Saccharomyces cerevisiae Organelles. Molecular \& Cellular Proteomics, 9(3), 431-45.

Zeller, W. E., Sullivan, M. L., Mueller-Harvey, I., Grabber, J. H., Ramsay, A., Drake, C., \& Brown, R. H. (2015). Protein Precipitation Behavior of Condensed Tannins from Lotus pedunculatus and Trifolium repens with Different Mean Degrees of Polymerization. Journal of Agricultural and Food Chemistry, 63(4), 1160-1168. 


\section{Figure Captions}

\section{Figure 1:}

A: Nitrogen and carbohydrate analyses performed on YPE and on its fractions obtained after centrifugation (removal of an insoluble part) and ultrafiltration on a $10 \mathrm{kDa}$ membrane. Results are expressed in \% dry weight.

B :1D-SDS PAGE analysis of YPE proteins, molecular weight standard MW on the left.

Figure 2: (A) Interactions between grape skin tannins (GST), red wine polyphenols (WP) or wine tannins (WT) and YPE. Results are expressed in mg removed polyphenols per gram of YPE. Reversibility upon dilution in the model wine for GST, WP and WT (B).

Figure 3: Results of Dynamic Light Scattering experiments performed between the polyphenols and A) the yeast protein extract (YPE); B) Mannoproteins (MPs) and C) Laminarin (b-glucan). Polyphenols were grape skin tannins (GST), red wine polyphenols (WP) and red wine tannins (WT). Is: intensity scattered at an angle of $90^{\circ}$ (Arbitrary Units), $\mathrm{D}_{\mathrm{H}}$ : hydrodynamic diameter. Results represent the intensity scattered by the controls and the $\mathrm{D}_{\mathrm{H}}$ of aggregates when present, the sum of these intensities (calculated), the intensity of the mixture and the $\mathrm{D}_{\mathrm{H}}$ of the aggregate formed. * The intensity scattered by the YPE-GST mixture after 15 min reached a value of 2200 .

Figure 4: Interaction of grape skin tannins (GST) (1), red wine tannins (WT) (2) and red wine polyphenols (WP) (3) with yeast protein extract or mannoproteins studied by ITC at 25 ${ }^{\circ} \mathrm{C}$ showing the thermograms and binding isotherms. ( $\left.\mathbf{a}_{1}, \mathbf{a}_{2}, \mathbf{a}_{3}\right)$ Blank experiments for injection of polyphenols at 5 g. $\mathrm{L}^{-1}$ in the wine-like solution. $\left(\mathbf{b}_{\mathbf{1}}, \mathbf{b}_{2}, \mathbf{b}_{\mathbf{3}}\right)$ Titration plots of polyphenols into 4 g. $\mathrm{L}^{-1}$ yeast protein extract. $\left(\mathbf{c}_{1}, \mathbf{c}_{2}, \mathbf{c}_{3}\right)$. Integrated peaks of yeast protein extract titration plots. $\left(\mathbf{d}_{\mathbf{1}}, \mathbf{d}_{\mathbf{2}}, \mathbf{d}_{\mathbf{3}}\right)$ Titration plots of polyphenols into $10 \mathrm{~g}$. $\mathrm{L}^{-1}$ mannoproteins for GST and 4 g. $L^{-1}$ mannoproteins for WT and WP. $\left(\mathbf{e}_{1}, \mathbf{e}_{2}, \mathbf{e}_{3}\right)$ Integrated peaks of mannoprotein titration plots. The mass ratio is the mass of polyphenols divided by the mass of either YPE or mannoprotein compounds.

Figure 5: Interaction of grape skin tannins (GST) (1) and red wine polyphenols (WP) (2) with yeast protein extract or mannoproteins studied by ITC at $10{ }^{\circ} \mathrm{C}$ showing the thermograms and binding isotherms. ( $\left.\mathbf{a}_{1}, \mathbf{a}_{2}, \mathbf{a}_{3}\right)$ Blank experiment for injection of polyphenols at 5 g.L $\mathrm{L}^{-1}$ in wine-like solution. $\left(\mathbf{b}_{1}, \mathbf{b}_{\mathbf{2}}, \mathbf{b}_{\mathbf{3}}\right)$ Titration plots of polyphenols into 4 g. $\mathrm{L}^{-1}$ yeast protein extract. $\left(\mathbf{c}_{\mathbf{1}}, \mathbf{c}_{2}, \mathbf{c}_{\mathbf{3}}\right)$ Integrated peaks of yeast protein extract titration plots. $\left(\mathbf{d}_{1}, \mathbf{d}_{2}, \mathbf{d}_{3}\right)$ Titration plots of polyphenols into 10 g. $\mathrm{L}^{-1}$ mannoproteins for GST and 4 g.L $\mathrm{L}^{-1}$ mannoproteins for WP. $\left(\mathbf{e}_{1}, \mathbf{e}_{2}, \mathbf{e}_{3}\right)$ Integrated peaks of mannoprotein titration plots. 
A

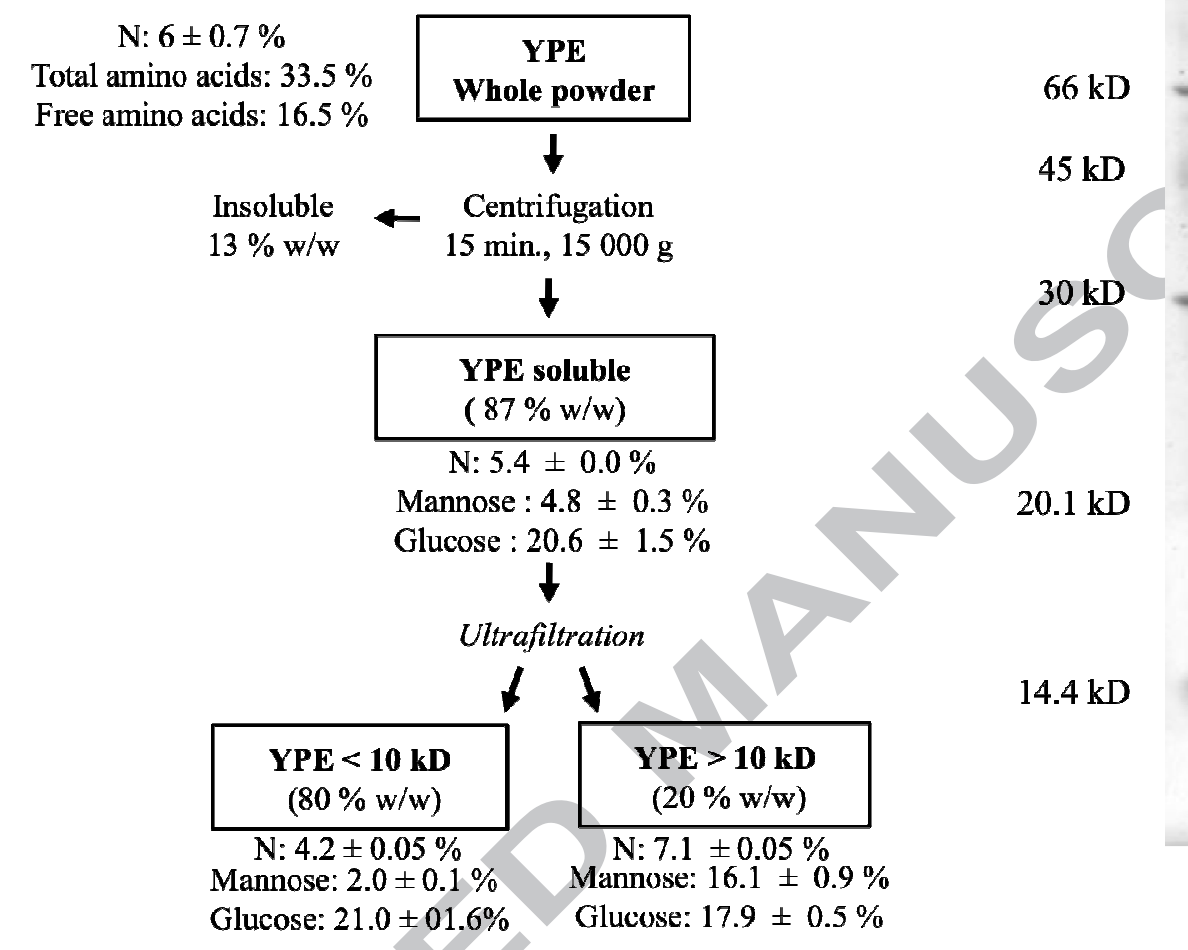

B

MW YPE

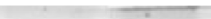

$6 \mathrm{kD}$

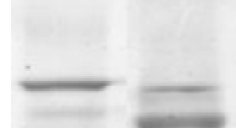

$45 \mathrm{kD}$

$30 \mathrm{kD}$

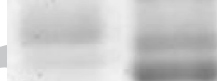

(1)

Figure 1 

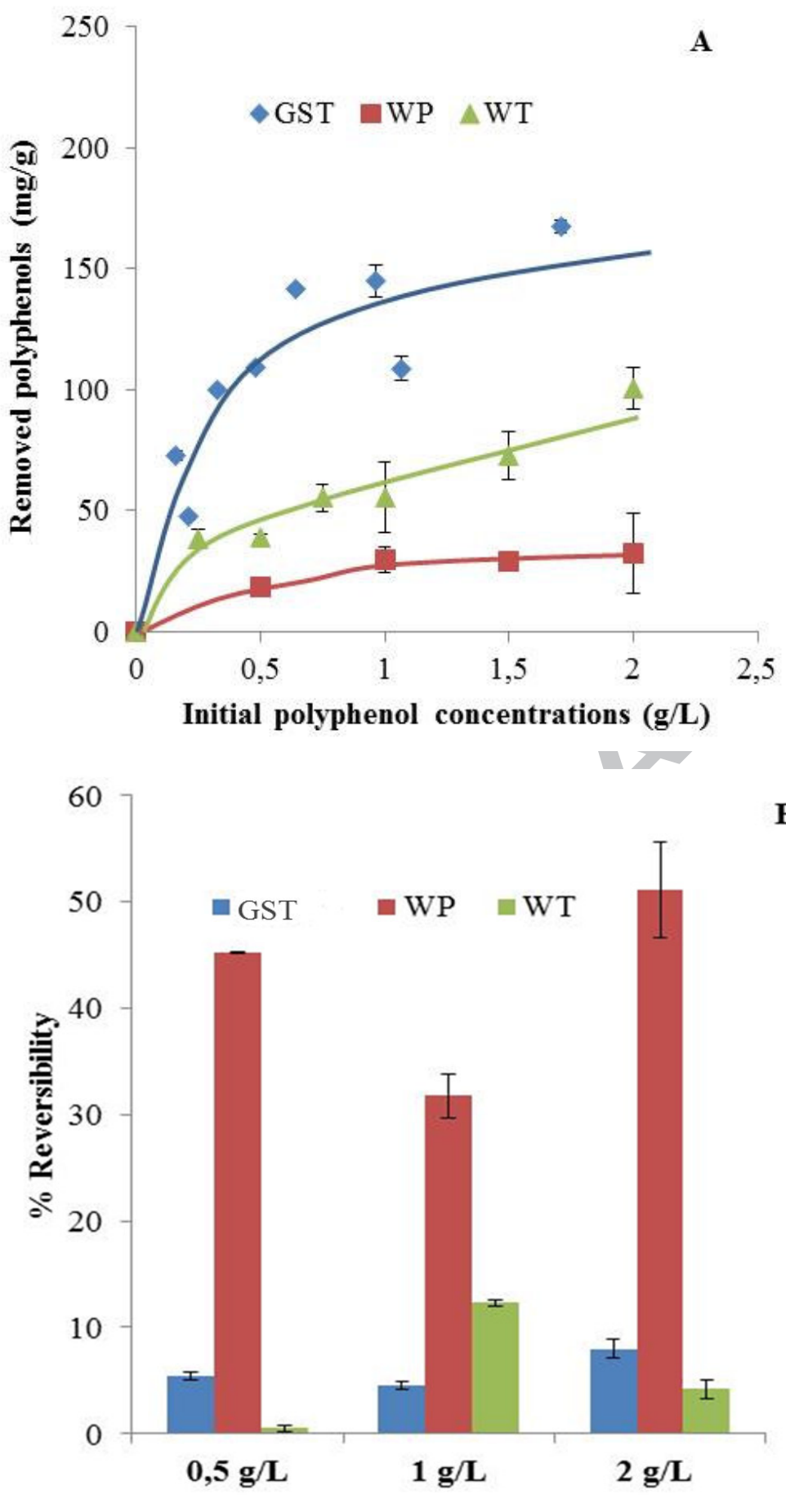

Mekoue et al. figure 2 

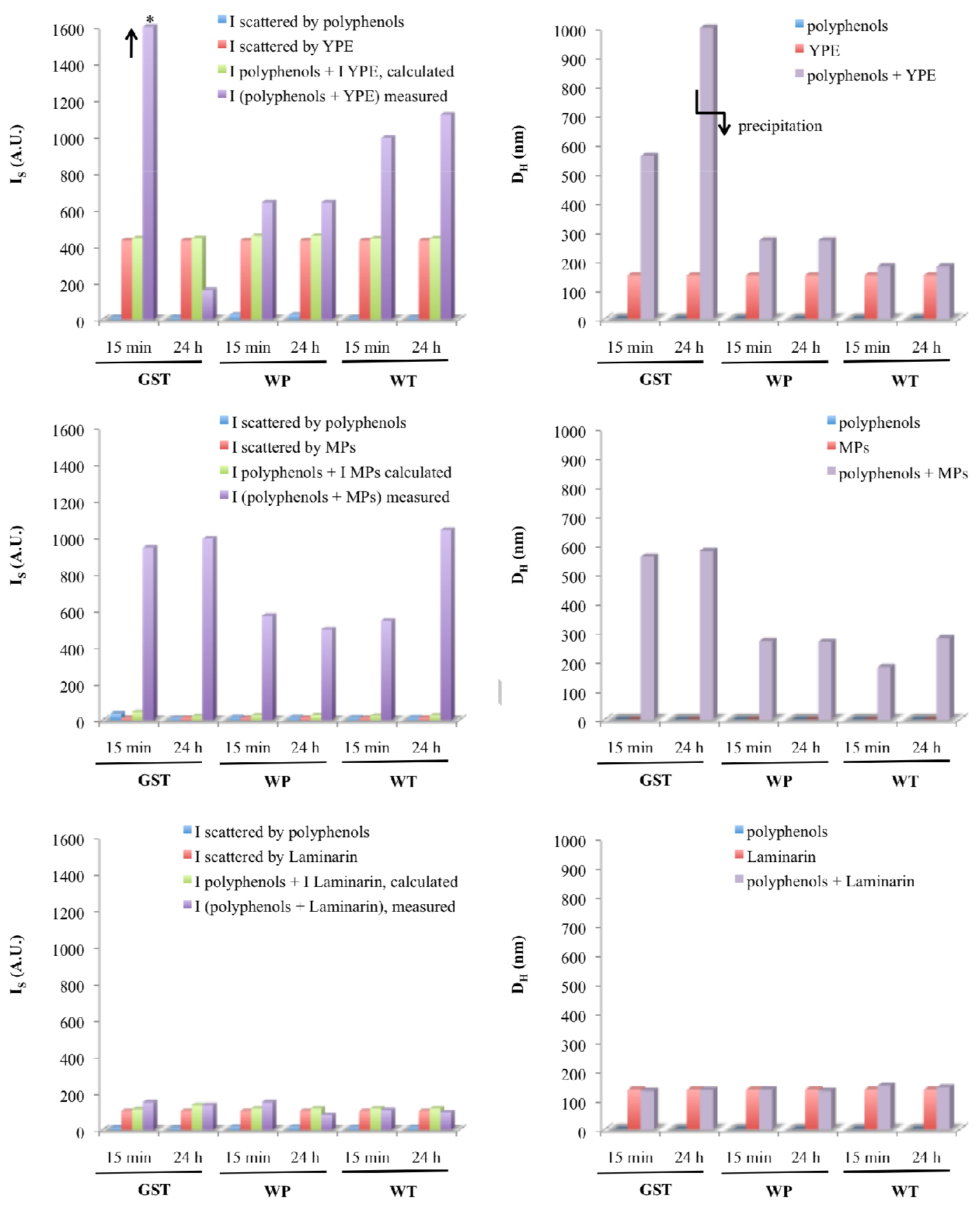

\section{Mekoue et al., Figure 3}


(1)

(2)
(3)

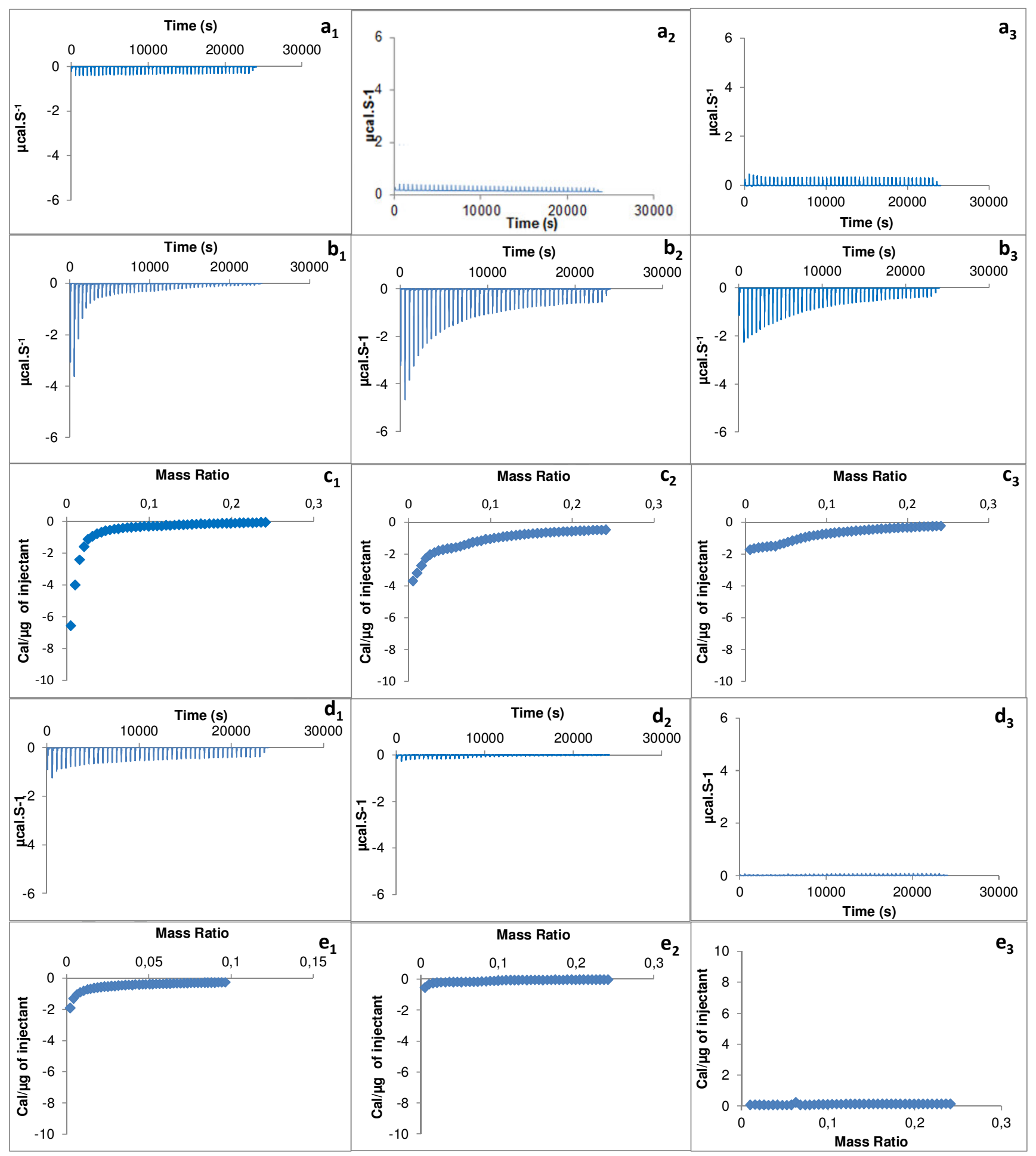

Mekoue et al, Figure 4 
(1)

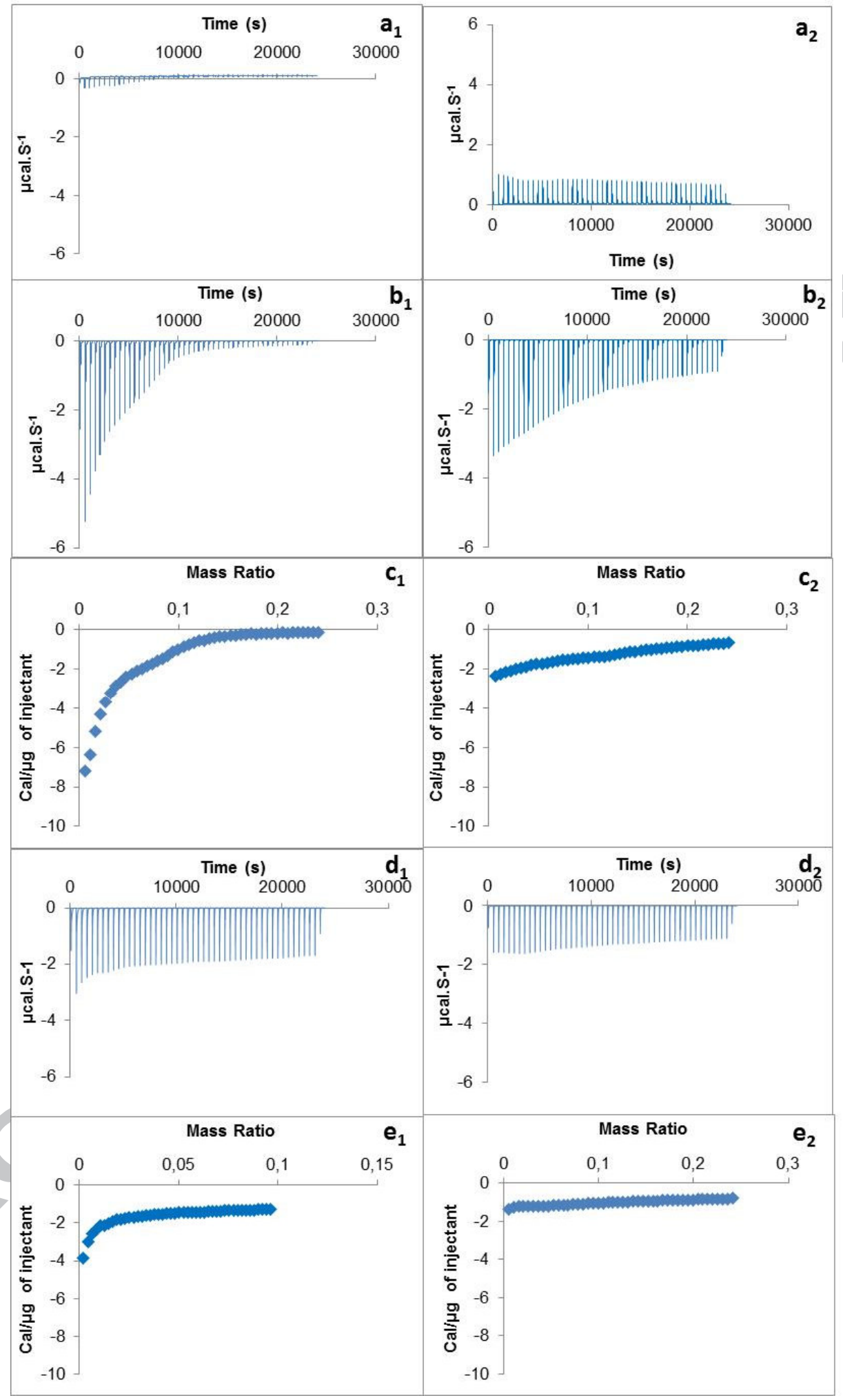

Mekoue et al., Figure 5 
Table 1: Analysis of the different polyphenols fractions obtained by HPLC before (monomers) and after depolymerization reactions. WP: red wine polyphenols; WT: red wine tannins (high molecular weight fraction purified from WP); GST: grape skin tannins.

\begin{tabular}{lcccc} 
& & WP & WT & GST \\
\cline { 3 - 5 } Tannins & aDP & $5.8 \pm 0.2$ & $7.5 \pm 0.2$ & $26.7 \pm 0.5$ \\
& \% Gallate & $3.9 \pm 0.6$ & $4.4 \pm 0.0$ & $5.4 \pm 0.1$ \\
& \% TriOH & $31.2 \pm 2$ & $26.5 \pm 0.2$ & $15 \pm 1$ \\
& Total $(\mathrm{mg} / \mathrm{g})$ & $170 \pm 15$ & $428 \pm 41$ & 930 \\
& Yield $(\%)$ & $21.2 \pm 0.3$ & $42.8 \pm 4.1$ & 93 \\
\hline & Anthocyanins & $33.1 \pm 1.6$ & & \\
Monomers & Flavan-3-nols & $8.7 \pm 0.7$ & & \\
$(\mathrm{mg} / \mathrm{g})$ & Phenol Acids & $36.9 \pm 3.6$ & & \\
& Stilbens & $27.3 \pm 0.2$ & & \\
& Flavonols & $6.7 \pm 0.6$ & & \\
\hline$\% \mathrm{~A}_{420} / \mathrm{A}_{280}{ }^{*}$ & Total $(\mathrm{mg} / \mathrm{g})$ & $112.7 \pm 6.7$ & & \\
$\% \mathrm{~A}_{460} / \mathrm{A}_{280}{ }^{*}$ & & $5.3 \pm 0.3$ & $7.3 \pm 0.4$ & \\
$\% \mathrm{~A}_{520} / \mathrm{A}_{280}$ & & $6.4 \pm 0.3$ & $7.7 \pm 0.4$ & \\
\hline
\end{tabular}

aDP: average degree of polymerization, $\%$ tri-OH:\% epigallocatechin.

*: from UV-visible spectrophotometric measurements in the model wine. 


\section{Highlights}

- Interactions of Polyphenols with Yeast Protein Extract, Mannoproteins and $\beta$-Glucans.

- Binding experiments, titration calorimetry and dynamic light scattering studies were done.

- Higher interactions for Yeast Protein Extract than Mannoproteins.

- No interaction leading to the formation of aggregates with $\beta$-glucan.

- Strong impact of the polyphenol structures and protein content on the interactions 